Paper is published as: Mater. Sci. Techn, 2001, vol. 17, 1324-28

\title{
The Effect of Compositional Variations on the Characteristics of Coarse Intermetallic Particles in Overaged 7xxx Al Alloys
}

\author{
X.-M. Li and M. J. Starink \\ Materials Research Group, School of Engineering Sciences, \\ University of Southampton, Southampton, SO17 1BJ, UK
}

\begin{abstract}
To provide an understanding of how compositional variations affect the characteristics of coarse intermetallic particles in 7xxx alloys, three Al-Zn-Mg-Cu-Zr aluminium alloy plates with different $\mathrm{Zn}, \mathrm{Mg}$ and $\mathrm{Cu}$ contents were studied by optical microscopy based image analysis, scanning electron microscopy (SEM), energy disperse X-ray spectroscopy (EDS) and differential scanning calorimetry (DSC). These coarse intermetallic particles are detrimental, especially to the toughness of the alloy. The experimental observations were interpreted successfully on the basis of the phase diagram and the temperature dependent $S$ phase solvus which was derived on the basis of the regular solution model. The temperature dependent $S$ phase solvus indicates that some compositions in the composition windows of 7050 and 7x75 type alloys will give rise to the detrimental S phase that can not be dissolved during solution treatment. Also the $\mathrm{T}$ phase is analysed and conditions for its formation and dissolution are discussed. It is shown that the present results can produce useful information on alloy design and thermo-mechanical processing via microstructural control.
\end{abstract}

\section{$\underline{\text { Introduction }}$}

The main properties of high strength $7 \mathrm{xxx}$ alloys as used predominantly in aircraft wing applications are the strength, toughness and stress corrosion cracking resistance. These properties are greatly determined by the main phases in the alloys, i.e. GP zones, $\eta^{\prime}, \eta, \mathrm{T}, \mathrm{S}, \mathrm{Mg}_{2} \mathrm{Si}$ and Ferich intermetallic phases. Thus, the balance of properties of 7xxx alloys can be optimised by microstructural modifications via alloy compositional changes and heat treatment variations [1]. Coarse (larger than $1 \mu \mathrm{m}$ ) intermetallic particles are generally detrimental to the properties, 
especially to the toughness, and in 7xxx alloys these particles are especially the Fe-rich and $\mathrm{S}$ $\left(\mathrm{Al}_{2} \mathrm{CuMg}\right)$ intermetallic phases [2]. Consequently, investigation into these intermetallic particles in 7xxx alloys with an aim to predict the properties is of key industrial interest.

The Al-Zn-Mg-Cu system is a highly complex one, with existing literature [3-6] indicating that at the $\mathrm{Al}$ end temperature between $400^{\circ} \mathrm{C}$ and the solidus, five intermetallic phases can occur (see Table 1$)$. Of these five, $\theta$ is essentially a binary phase $\left(\mathrm{Al}_{2} \mathrm{Cu}\right), \mathrm{S}$ is essentially ternary $\left(\mathrm{Al}_{2} \mathrm{CuMg}\right)$, whilst $\eta, T$ and $Z$ are solid solutions with extended composition ranges containing all four elements. Of these five phases only $\eta$, $T$ and $S$ appear in commercial 7xxx alloys.

The objective of this work is to provide an understanding of how compositional variations and heat treatments affect the characteristics of intermetallic particles in 7xxx alloys. We will specifically interpret the presence of $\mathrm{S}$ and $\mathrm{T}$ phase using the phase diagrams as well as a regular solution model for the $\mathrm{S}$ phase solvus. An analysis of coarse intermetallic particles in three alloys is presented. Compared with typical (7050/7x75) type compositions, one alloy has a high Cu content, one has a high $\mathrm{Mg}$ content, whilst the third one has medium $\mathrm{Cu}$ and $\mathrm{Mg}$ contents.

\section{Experimental}

Three Al-Zn-Mg-Cu-Zr alloys, with Zn, $\mathrm{Mg}$ and $\mathrm{Cu}$ levels broadly in the range of 7010, 7050 to 7075 compositions were studied. The alloys were produced at the Defence Evaluation and Research Agency (DERA), Farnborough, UK, and processed to plate of $25 \mathrm{~mm}$ thickness. The measured (by optical emission spectroscopy (OES)) chemical compositions of the alloys investigated as well as the composition ranges for 7010, 7050 and 7075 commercial alloys are shown in Table 2. All alloys contain 0.02 wt $\% \mathrm{Ti}$ and $0.12 \mathrm{wt} \% \mathrm{Zr}$. $99.90 \%$ aluminium was used as base to ensure $\mathrm{Fe}<0.15 \%$ and $\mathrm{Si}<0.1 \%$. All three alloys were solution treated at temperatures ranging from 437 to $485^{\circ} \mathrm{C}$ (mostly $475^{\circ} \mathrm{C}$ was used) for $1 \mathrm{~h}$ and subsequently aged to T7 temper (artificial ageing).

A digital image analysis software package [7] linked to an optical microscope was employed for analysis of grain structure and particles in the samples. Each alloy was cut at about half thickness along the three main planes, i.e. the L-T, T-S and L-S planes ( $\mathrm{L}=$ longitudinal rolling direction, $\mathrm{T}=$ long transverse and $\mathrm{S}=$ short transverse). Specimens were ground and subsequent polishing was performed using $6 \mu \mathrm{m}, 1 \mu \mathrm{m}$ and finally $1 / 4 \mu \mathrm{m}$ diamond paste. For grain structure examination, samples were etched in $10 \mathrm{~cm}^{3} \mathrm{H}_{3} \mathrm{PO}_{4}$ plus $90 \mathrm{~cm}^{3}$ distilled water at $50^{\circ} \mathrm{C}$ for one minute. In order to average out possible variations as a function of distance to the surface of the plate, average volume fractions of coarse particles in the T-S and L-S planes are reported. 
Two samples were selected for Scanning Electron Microscopy (SEM) / Energy Disperse X-ray Spectroscopy (EDS) analysis: the high Cu alloy B and the high Mg alloy C. The SEM facility was a Jeol JSM-6400. Chemical compositions of various particles in the samples were determined using EDS.

Table 1 Intermetallic phases in Al-rich Al-Zn-Mg-Cu alloys. The various compositions and phase indications suggested in the literature $[3,4,6]$ have been included in the table.

\begin{tabular}{|c|c|c|}
\hline $\begin{array}{c}\text { Phase indications } \\
\text { (alternative) }\end{array}$ & $\begin{array}{l}\text { Composition in Al-Zn-Mg } \\
\text { (alternative indications) }\end{array}$ & $\begin{array}{c}\text { Composition in Al-Cu-Mg } \\
\text { (alternative indications) }\end{array}$ \\
\hline$\theta$ & - & $\mathrm{Al}_{2} \mathrm{Cu}$ \\
\hline $\mathrm{Z}$ & $\mathrm{Mg}_{2} \mathrm{Zn}_{11}$ & $\mathrm{Cu}_{6} \mathrm{Mg}_{2} \mathrm{Al}_{5}$ \\
\hline S & - & $\mathrm{Al}_{2} \mathrm{CuMg}$ \\
\hline $\mathrm{T}(\tau)$ & $\begin{array}{c}\text { AlMgZn }\left(\mathrm{Mg}_{3} \mathrm{Zn}_{3} \mathrm{Al}_{2}, \mathrm{Al}_{6} \mathrm{Mg}_{11} \mathrm{Zn}_{11},\right. \\
\left.(\mathrm{Al}, \mathrm{Zn})_{49} \mathrm{Mg}_{32}\right)\end{array}$ & $\mathrm{CuMg}_{4} \mathrm{Al}_{6} *$ \\
\hline$\eta(\mathrm{M}, \sigma)$ & $\operatorname{MgZn}_{2},\left((\mathrm{Al}, \mathrm{Zn})_{2} \mathrm{Mg}\right)$ & $\operatorname{AlCuMg}\left(\mathrm{Al}_{6} \mathrm{Cu}_{4} \mathrm{Mg}_{2}\right)$ \\
\hline
\end{tabular}

* Note that the existence of the cubic phase $\mathrm{CuMg}_{4} \mathrm{Al}_{6}\left(\operatorname{Im}_{3}\right.$ structure $\left.[3,10]\right)$ appearing in phase diagrams by Mondolfo [3,10] and Strawbridge et al. [4], has not been confirmed in Ref. [6]. This indicates that $\mathrm{Zn}$ is essential for the stability of the cubic $\mathrm{T}$ phase.

Table 2 Chemical compositions of three 7xxx alloys studied and commercial 7xxx alloys (wt\%)

\begin{tabular}{ccccc}
\hline Alloy & Zn & Mg & $\mathrm{Cu}$ & $\begin{array}{c}\mathrm{Al}, \mathrm{Zr}, \mathrm{Ti}, \mathrm{Cr} \& \\
\text { impurities }\end{array}$ \\
\hline A & 5.94 & 2.34 & 1.79 & Remainder \\
B & 6.12 & 2.34 & 2.58 & \\
C & 6.51 & 2.96 & 1.91 & \\
7010 & $5.7-6.7$ & $2.1-2.6$ & $1.5-2.0$ & \\
7050 & $5.7-6.7$ & $1.9-2.6$ & $2.0-2.6$ & \\
7075 & $5.1-6.1$ & $2.1-2.9$ & $1.2-2.0$ & \\
\hline
\end{tabular}


A Shimadzu DSC-50 (heat-flux type) was employed for the Differential Scanning Calorimetry (DSC) experiments. The DSC samples were machined from the 7xxx plates to $5 \mathrm{~mm}$ in diameter and $1 \mathrm{~mm}$ in thickness with average mass of about $63 \mathrm{mg}$. A pure aluminium reference (99.9\%) with a mass and shape close to that of the sample was used. The heating rate was $10^{\circ} \mathrm{C} / \mathrm{min}$. Further details of the DSC experimental procedures are presented elsewhere [8].

\section{$\underline{\text { Results and Discussion }}$}

\section{MICROSCOPY}

Optical microscopy and SEM revealed a partially recrystallised grain structure for all alloys with small amounts of intermetallic particles. Image analysis was used to quantify the volume fraction of coarse particles. The results also indicate that the high $\mathrm{Cu}$ alloy has the highest percentage of coarse particles with an average of $2.6 \%$, whilst the high $\mathrm{Mg}$ alloy and the alloy with medium $\mathrm{Cu}$ and medium Mg have similar volume fractions of about $1.7 \%$. This implies that Cu content plays an important role in the formation of coarse particles.

SEM micrographs of alloy B and alloy C are presented in Fig. 1. The identification of specific particles was obtained from compositional analysis using EDS, examples of which are presented in Table 3. Note that in all cases the $\mathrm{Al}$ matrix contributes to the compositional analysis.

For alloy B, the detected particles are mostly $\mathrm{S}$ phase (diameter $\sim 3 \mu \mathrm{m}$, evenly distributed particles) and $\mathrm{Al}_{7} \mathrm{Cu}_{2} \mathrm{Fe}$ (typically $\sim 15 \mu \mathrm{m}$, clustered in bands), whilst for alloy $\mathrm{C}$, the detected particles are mostly S phase, with a few $\mathrm{Al}_{7} \mathrm{Cu}_{2} \mathrm{Fe}$ and $\mathrm{Si}$ containing particles, and a complex phase containing $\mathrm{Cu}, \mathrm{Mg}$, $\mathrm{Zn}$ and probably $\mathrm{Al}$, but due to the contribution of the matrix to the EDS signal the latter could not be directly determined. In view of the relatively small amounts of the latter phase, identification by X-ray diffraction analysis was not attempted, and instead the phase was identified on the basis of the measured EDS compositions. To achieve this identification it is first noted that existing literature and phase diagrams indicate that the phase can only be the $\mathrm{T}$ or $\eta$ phase. Phase diagram data for $6 \mathrm{wt} \% \mathrm{Zn}$ alloys at $460^{\circ} \mathrm{C}$ by Strawbridge et al. [4] and data for 6wt\%Zn, 1wt\% Cu alloys by Zakharov [9] indicate that $\eta$ phase can not be stable at and above $460^{\circ} \mathrm{C}$ for compositions in the vicinity of that of Alloy C. Also, the typical Cu:Mg ratio for $\eta$ phase of 1 as indicated by phase diagrams in [4] is inconsistent with measured Cu:Mg ratios, thus tending to exclude $\eta$ phase. In a further analysis, the measured EDS compositions were compared with composition ranges proposed for the $T$ and $\eta$ phases, as given in $[3,4]$, whilst taking a contribution 
to the EDS signal by the Al-rich matrix into account by assuming that the EDS signal is a weighted average of particle and matrix contributions. This procedure, which is described in detail in the Appendix, showed that the EDS signal is consistent with the particle being $\mathrm{T}$ phase and the calculated composition of the $\mathrm{T}$ phase particles is about $\mathrm{Al}_{40} \mathrm{Cu}_{15} \mathrm{Mg}_{25} \mathrm{Zn}_{20}$, illustrating that $\mathrm{T}$ phase is a quaternary phase which can be thought of as resulting from the extended solubility of $\mathrm{Cu}$ and $\mathrm{Al}$ in the $\mathrm{Mg}_{3} \mathrm{Zn}_{3} \mathrm{Al}_{2}$ phase.

Table 3 EDS compositional analysis of typical particles (at\%). In all cases, the $\mathrm{Al}$ matrix contributes to the compositional analysis.

\begin{tabular}{cccccccccl}
\hline \multirow{2}{*}{ Alloy } & Particle & $\mathrm{Al}$ & $\mathrm{Cu}$ & $\mathrm{Mg}$ & $\mathrm{Zn}$ & $\mathrm{Fe}$ & $\mathrm{Si}$ & $\mathrm{Zr}$ & Identification \\
\hline \multirow{2}{*}{$\mathrm{B}$} & type 1 & 70.8 & 14.4 & 13.4 & 1.31 & 0.04 & 0.00 & 0.03 & $\mathrm{~S}\left(\mathrm{Al}_{2} \mathrm{CuMg}\right)$ \\
& type 2 & 79.8 & 13.4 & 0.0 & 0.94 & 5.90 & 0.00 & 0.00 & $\mathrm{Al}_{7} \mathrm{Cu}_{2} \mathrm{Fe}$ \\
& & & & & & & & & \\
$\mathrm{C}$ & type 1 & 56.9 & 20.0 & 21.5 & 1.67 & 0.00 & 0.00 & 0.00 & $\mathrm{~S}\left(\mathrm{Al}_{2} \mathrm{CuMg}\right)$ \\
& type 3 & 72.3 & 5.6 & 12.8 & 9.21 & 0.12 & 0.00 & 0.00 & $\mathrm{~T}$ \\
& type 2 & 88.7 & 5.4 & 1.7 & 2.14 & 2.02 & 0.00 & 0.00 & $\mathrm{Al}_{7} \mathrm{Cu}_{2} \mathrm{Fe}$ \\
& type 4 & 88.1 & 0.7 & 1.9 & 3.46 & 0.00 & 5.76 & 0.02 & unidentified \\
\hline
\end{tabular}

DSC

Fig. 2 shows a DSC curve with three runs of alloy B solution treated at $475^{\circ} \mathrm{C}$ and aged to the T7 condition. Comparison with other work [11,12,13] allows identification of the heat effects: peak I corresponds to the dissolution of $\eta^{\prime}$, II the formation of $\eta$ and III the dissolution of $\eta$. In an earlier work, Effects IV and V were discussed and ascribed to the formation of S phase and the dissolution of S phase, respectively [13]. As will be discussed below, this identification is consistent with solvus data of phase to be presented in the next section. Effect VII is due to the melting of undissolved S phase [2,13]. Effect VI corresponds to the melting of $\mathrm{T}$ phase and is only observed in the third DSC run. This indicates that after very slow cooling $\left(2^{\circ} \mathrm{C} / \mathrm{min}\right)$, there was not sufficient time for the coarse $\mathrm{T}$ phase to be completely dissolved, and hence a melting of $\mathrm{T}$ phase occurred at $480^{\circ} \mathrm{C}$. The difference between the three DSC runs was caused by the heating cycles of DSC, for instance, in the second run the first exothermic peak corresponds to the $\eta^{\prime}$ precipitation and there is 
a GP zone dissolution effect prior to the $\eta^{\prime}$ precipitation effect. In the following discussion, the focus is placed on the heat effects of the first DSC run since it is the most important heating cycle reflecting reactions in a solution treated, quenched and aged sample.

The DSC curves of three alloys solution treated at $475^{\circ} \mathrm{C}$ and aged to $\mathrm{T} 7$ condition is shown in Fig. 3. It is noticed that the high $\mathrm{Cu}$ alloy $\mathrm{B}$ has the strongest $\mathrm{S}$ melting peak, followed by the high Mg alloy $\mathrm{C}$ and medium $\mathrm{Cu}$ and $\mathrm{Mg}$ alloy $\mathrm{A}$.

\section{CONDITIONS FOR THE PRESENCE OF S AND T PHASE}

In interpreting the results, we will make use of published phase diagrams at $460^{\circ} \mathrm{C}$ as well as a temperature dependent solvus diagram for $\mathrm{S}$ phase which we will derive below. For the latter, we use a regular solution model $[14,15]$. In this model the solvus related to an intermetallic phase $\mathrm{M}_{\mathrm{m}} \mathrm{A}_{\mathrm{a}} \mathrm{B}_{\mathrm{b}} \mathrm{C}_{\mathrm{c}}$ ( $\mathrm{M}$ is the main constituent of the alloy, and $\mathrm{A}, \mathrm{B}, \mathrm{C}$ are the alloying elements) is given by [13]:

$$
\left(c_{A}\right)^{a}\left(c_{B}\right)^{b}\left(c_{C}\right)^{c}=c_{o} \exp \left[\frac{-H_{\text {sol }}}{k_{B} T}\right]
$$

where $\mathrm{H}_{\text {sol }}$ is the solution enthalpy, $\mathrm{k}_{\mathrm{B}}$ is the Boltzmann constant, $\mathrm{T}$ is the temperature. If appropriate values for $\mathrm{H}_{\mathrm{sol}}, \mathrm{c}_{0}$, a, b and c for each phase can be derived from available solubility and compositional data, a phase diagram can be constructed. However, only for $\mathrm{T}=460^{\circ} \mathrm{C}$ significant data on the solvi of all phases are available [4]. For the $S$ phase, $H_{\text {sol }}(S)$ has been determined before [8], and by combining solvus data at $460^{\circ} \mathrm{C}$ with $\mathrm{H}_{\text {sol }}$ the $\mathrm{S}$ solvus as a function of the temperature can be estimated, as plotted in Fig. 4.

The S phase solvus (Fig. 4) indicates that at a solution treatment temperature of $475^{\circ} \mathrm{C}$, alloys $\mathrm{B}$ and $C$ are in the $(\alpha+S)$ field, thus $S$ phase can not be dissolved in these alloys at this temperature. Alloy A is practically on the $\mathrm{S}$ phase solvus, and given sufficient solution treatment time, $\mathrm{S}$ phase would be expected to dissolve. However, some compositional segregation originating from the solidification process can cause $\mathrm{S}$ phase to remain present even after long solution treatment times. The observed $S$ phase melting peaks in Fig. 3 are in line with this interpretation. Fig. 4 indicates that dissolution of $\mathrm{S}$ phase is possible for alloy $\mathrm{C}$ through increasing the solution temperature to just below $490^{\circ} \mathrm{C}$, whilst complete dissolution of $\mathrm{S}$ phase is impossible for alloy $\mathrm{B}$. For the high $\mathrm{Mg}$ alloy $\mathrm{C}$, both $\mathrm{S}$ melting at $490^{\circ} \mathrm{C}$ and $\mathrm{T}$ melting at $480^{\circ} \mathrm{C}$ were present. The latter may seem surprising as, according to the phase diagram of Al-Zn-Mg-Cu alloys with $6 \mathrm{wt} \% \mathrm{Zn}$ at $460^{\circ} \mathrm{C}$ (Fig. 5, based on data from Strawbridge et al. [4]), T phase only appears for alloys with $\mathrm{Mg}$ content 
higher than 3.2wt\%, i.e. alloy $\mathrm{C}$, which contains $3.0 \mathrm{wt} \% \mathrm{Mg}$ is within the $\alpha+\mathrm{S}$ phase field. However, the $\alpha+S+T$ phase field in the phase diagram at compositions around alloy $C$ expands substantially with increasing Zn content, such that for a Zn content of $8 \mathrm{wt} \%$ at $460^{\circ} \mathrm{C}$, $\mathrm{T}$ phase is stable for Mg contents as low as $2.7 \mathrm{wt} \%$ [4]. This suggests that alloy C, at the solution treatment temperatures used, may be in or very close to the $\alpha+S+T$ phase field. A small amount of $\mathrm{Mg}$ segregation, which originates from the solidification processing and which is not entirely removed during the thermomechanical and thermal processing, can thus cause the presence of $\mathrm{T}$ phase in alloy C. This finding will have consequences for solution treatment practice of 7xxx alloys, i.e. the 7050 and 7010 alloys which have Mg contents lower than 2.6wt\%, are not expected to contain $\mathrm{T}$ phase and, provided they are well homogenised, they can be solution treated up to the incipient melting temperature of S phase $\left(490^{\circ} \mathrm{C}\right)$. However, for alloys with $\mathrm{Mg}$ contents at the high end of the 7075 composition range (2.9wt\%), some $\mathrm{T}$ phase can be present and they should be solution treated below the melting point of $\mathrm{T}$ phase $\left(480^{\circ} \mathrm{C}\right)$.

In general, the DSC data on S phase and T phase melting are in good agreement with the SEM/EDS observations. It is also noted that the identification of effect $\mathrm{V}$ in the DSC curve of the high $\mathrm{Cu}$ alloy B (Fig. 2) as due to the dissolution of S phase is consistent with the S phase solvus in Fig. 4, as the latter indicates that on heating, substantial S phase dissolution should occur from about $440^{\circ} \mathrm{C}$. On further heating, the original solution treatment temperature will be reached and further dissolution of S phase would involve the coarse S phase particles left undissolved after the solution treatment $\left(475^{\circ} \mathrm{C}\right)$. As dissolution of these coarse particles will be slow, the $\mathrm{S}$ phase dissolution effect during DSC heating would be expected to decrease substantially at this temperature. This explains why the $\mathrm{S}$ phase dissolution effect is situated between about 440 and $475^{\circ} \mathrm{C}$, and lends further support to our earlier interpretation of effect V (in Ref. [13] and the previous section).

In order to further investigate the presence of $\mathrm{T}$ phase in the high $\mathrm{Mg}$ alloy $\mathrm{C}$ and confirm our interpretations, samples were solution treated for $1 \mathrm{~h}$ at 437, 452, 467 and $485^{\circ} \mathrm{C}$. In samples solution treated at 437,452 and $467^{\circ} \mathrm{C}$ two melting peaks, corresponding to T melting at $480^{\circ} \mathrm{C}$ and S melting at $490^{\circ} \mathrm{C}$, were observed, see Fig. 6 . These DSC curves show that the $\mathrm{T}$ phase melting peak decreases with increasing solution treatment temperature. Additional SEM/EDS studies on alloy $\mathrm{C}$ solution treated at $485^{\circ} \mathrm{C}$ revealed that the $\mathrm{T}$ phase had totally disappeared. These results indicate that the $\mathrm{T}$ phase, which is thought to form during casting, is not stable at the solution treatment temperatures employed and that with increasing solution treatment temperature the $\mathrm{T}$ phase either dissolves, to be replaced by S phase, or transforms directly to S phase. 


\section{$\underline{\text { Conclusions }}$}

In DSC scans of solution treated high Cu and high Mg 7xxx alloys, substantial melting of S phase at $490^{\circ} \mathrm{C}$ was observed. In the alloy with medium $\mathrm{Cu}$ and $\mathrm{Mg}$ content very little $\mathrm{S}$ phase melting was observed. Melting of $\mathrm{T}$ phase at $480^{\circ} \mathrm{C}$ was observed only for the alloy with high $\mathrm{Mg}$ content. DSC as well as SEM indicate that in the high $\mathrm{Mg}$ alloy the main coarse particles are $\mathrm{S}\left(\mathrm{Al}_{2} \mathrm{CuMg}\right)$ and $\mathrm{T}$ phase, whilst in the high $\mathrm{Cu} 7 \mathrm{xxx}$ alloy the main coarse particles are $\mathrm{S}$ and $\mathrm{Al}_{7} \mathrm{Cu}_{2} \mathrm{Fe}$. The high $\mathrm{Cu}$ alloy has the highest volume fraction of coarse particles. These observations can be interpreted well on the basis of the phase diagram and the temperature dependent $\mathrm{S}$ phase solvus based on the regular solution models. It is shown that some compositions in the composition windows of 7050 and 7x75 type alloys will give rise to the detrimental S phase which can not be dissolved during solution treatment. Results indicate that $\mathrm{T}$ phase is present only if $\mathrm{Mg}$ content approaches the high $\mathrm{Mg}$ end of the composition range for the 7075 alloy.

\section{Acknowledgements}

The financial support from Alcoa Europe (formerly British Aluminium Plate) is gratefully acknowledged. Technical discussions with Drs J. Newman, A. J. Morris, S. Khosla and S. Waters (Alco Europe) and Dr P.D. Pitcher (DERA, Farnborough), and additional DSC and image analysis work by Mr. O. Rousseau are gratefully acknowledged.

\section{$\underline{\text { Appendix }}$}

If the area sampled by EDS contains 2 or more phases, the determined composition will be an average of the composition of the phases present, and deriving the composition of the individual phases is a non-trivial problem. We will analyse this problem using a mathematical analysis, some elements of which (specifically Eqs. 1-3) were presented elsewhere [16], and apply it to the EDS analysis data of the particles in Alloy $\mathrm{C}$ that contained $\mathrm{Cu}, \mathrm{Mg}$ and $\mathrm{Zn}$. In the analysis, vector notation will be used and the composition vector, $\vec{x}$, is defined as: 


$$
\vec{x}=\left(\begin{array}{c}
x_{A} \\
x_{B} \\
x_{C} \\
\ldots \\
\ldots
\end{array}\right)
$$

where A, B, C .. etc. are the (major) elements present in the alloy. In the following we will assume that the ZAF type correction applied in the standard EDS software used is, at least in good approximation, valid for the multiphase samples considered. Under this assumption, measured EDS compositions, $\vec{x}_{E D S}$, should be a linear combination of the compositions of the individual phases:

$$
\vec{x}_{E D S}=\sum_{i} f_{P_{i}} \vec{x}_{P_{i}}^{e}
$$

where $P_{i}$ are the phases present in the alloy and $f_{P i}$ are the fractions at which these respective phases contribute to the EDS signal. If the accuracy of the determination of the composition is similar for all elements, and $i$ is smaller than the number of elements analysed, the values of the fractions $f$ can be determined by minimising the expression:

$$
\left|\vec{X}_{E D S}-\sum_{i} f_{P_{i}} \vec{X}_{P_{i}}^{e}\right|=\chi
$$

The accuracy of the various assumptions and the expected compositions is reflected in the value of $\chi$ obtained - the smaller $\chi$, the greater the accuracy.

In the present paper we want to make the distinction between $\mathrm{T}$ and $\eta$, based on EDS data which contains a contribution from the matrix. Whilst the composition of matrix, $\vec{x}_{M}$, can be estimated quite well (it should be given by the solvus at the solution treatment temperature, and is given in Table 4), the compositions of $\mathrm{T}$ and $\eta$ phase are at the outset not known. However, this problem can be resolved as follows. We first assume that for the narrow range of compositions of our alloys all possible $\mathrm{T}$ and $\eta$ phase compositions can be approximated by a linear combination of two compositions (see e.g. phase diagram data from Mondolfo [3]), i.e. for T phase:

$$
\vec{x}_{T}=\lambda_{T} \vec{x}_{T}^{a}+\left(1-\lambda_{T}\right) \vec{x}_{T}^{b}
$$


where $\vec{x}_{T}^{a}$ and $\vec{x}_{T}^{b}$ are two possible compositions of T phase (at the extremes of the stability range, e.g. a $\mathrm{Cu}$ lean and a $\mathrm{Zn}$ lean composition) and $\lambda_{T}$ is a parameter between 0 and 1 . Thus, if an analysed particle is $\mathrm{T}$ phase then the composition measured by EDS should be given by:

$$
\vec{X}_{E D S}=\lambda_{1} \vec{X}_{M}+\left(1-\lambda_{1}\right)\left[\lambda_{T} \vec{X}_{T}^{a}+\left(1-\lambda_{T}\right) \vec{X}_{T}^{b}\right]
$$

where $\lambda_{1}$ is between 0 and 1 . A similar equation is valid for EDS analysis of $\eta$ phase:

$$
\vec{x}_{E D S}=\lambda_{2} \vec{x}_{M}+\left(1-\lambda_{2}\right)\left[\lambda_{\eta} \vec{x}_{\eta}^{a}+\left(1-\lambda_{\eta}\right) \vec{x}_{\eta}^{b}\right]
$$

where $\lambda_{2}$ is between 0 and 1 . The deviations are defined as:

$$
\chi_{T}=\mid \vec{x}_{E D S}-\lambda_{1} \vec{x}_{M}+\left(1-\lambda_{1}\right)\left[\lambda_{T} \vec{x}_{T}^{a}+\left(1-\lambda_{T}\right) \vec{x}_{T}^{b}\right]
$$

and, analogously:

$$
\chi_{\eta}=\mid \vec{x}_{E D S}-\lambda_{2} \vec{x}_{M}+\left(1-\lambda_{2}\right)\left[\lambda_{\eta} \vec{x}_{\eta}^{a}+\left(1-\lambda_{\eta}\right) \vec{x}_{\eta}^{b}\right]
$$

Next, optimised values of the $\lambda$ parameters are calculated by minimising $\chi_{\mathrm{T}}$ and $\chi_{\eta}$, and the values obtained for $\chi_{\mathrm{T}}$ and $\chi_{\eta}$ are compared. For the particles in Alloy $\mathrm{C}$ which contain $\mathrm{Mg}, \mathrm{Cu}$ and $\mathrm{Zn}$ it was found that $\chi_{\mathrm{T}}=10$ (i.e. the average deviation is about 2.5 at\% per alloying element) with always $\chi_{\mathrm{T}}<\chi_{\eta}$. This indicates that the measured compositions of these particles are consistent with them being $\mathrm{T}$ phase.

As an extension of the method outlined, we can calculate the composition of the particles using (see [16]):

$$
\vec{x}_{P_{j}}=\frac{\vec{x}_{E D S}-\lambda_{1} \vec{x}_{M}}{\left\|\vec{x}_{E D S}-\lambda_{1} \vec{x}_{M}\right\|}
$$

with

$$
\|\bar{x}\|=x_{A}+x_{B}+x_{C} \ldots e t c
$$

For the particles in alloy $\mathrm{C}$, this yields a composition of $\mathrm{Al}_{40} \mathrm{Cu}_{15} \mathrm{Mg}_{25} \mathrm{Zn}_{20}$. 
Table 4 Composition of matrix, and compositions of $\mathrm{T}$ and $\eta$ phase estimated from data in Refs. $[3,10]$, as used for the analysis of EDS data (see Appendix).

\begin{tabular}{|l|r|r|r|r|l|}
\hline & \multicolumn{1}{|c|}{$\mathrm{Al}$} & \multicolumn{1}{l|}{$\mathrm{Zn}$} & \multicolumn{1}{c|}{$\mathrm{Mg}$} & $\mathrm{Cu}$ & estimated from \\
\hline matrix & 93.2 & 2.77 & 3.22 & 0.81 & $\alpha$ rich phase at $475^{\circ} \mathrm{C}$, Fig. 5 \\
\hline$\vec{x}_{T}^{a}$ (Cu lean composition) & 31 & 41 & 28 & 0 & {$[3]$} \\
\hline$\vec{x}_{T}^{b}$ (Zn lean composition) & 45 & 0 & 35 & 20 & {$[3,10]$} \\
\hline$\vec{x}_{\eta}^{a}$ (Cu lean composition) & & 67 & 33 & & {$[3]$} \\
\hline$\vec{x}_{T}^{b}$ (Zn lean composition) & 35 & 0 & 35 & 30 & {$[3]$} \\
\hline
\end{tabular}

\section{References}

1. I. J. POLMEAR, 'Light Alloys -Metallurgy of the Light Metals’, 1995, St. Edmundsbury Press Ltd, UK.

2. A. J. MORRIS, R. F. ROBEY, P. D. COUCH and E. DE LOS RIOS, Mater. Sci. Forum, 1997, 242, 181.

3. L.F. MONDOLFO, ‘Aluminium Alloys’, 1976, Butterworths \& Co Ltd, London.

4. D. J. STRAWBRIDGE, W. HUME-ROTHERY and A. T. LITTLE, J. Inst. Metals, 1948, 74, 191.

5. J.A. WERT, Scr. Metall., 1981, 15, 445.

6. P. VILLARS, A. PRINCE and H. OKAMOTO, ‘ASM Handbook of Ternary Alloy Diagrams', 1995, ASM International, Materials Park, Ohio.

7. J. BOSELLI, P. PITCHER, P. J. GREGSON and I. SINCLAIR, J. Microscopy, 1998, 194, 483.

8. M. J. STARINK and P. J. GREGSON, Mater. Sci. Eng A.,1996, 211, 54.

9 A.M. ZAKHAROV, Tsvet. Metally, 1961, 1, 124.

10 L.F. MONDOLFO, Metall. Rev, 1971, 16, 95.

11. C. GARCIA-CORDOVILLA, Mater. Sci. Eng A, 1991, 132, 135.

12. A. DESCHAMPS, Y. BRECHET, P. GUYOT and F. LIVET, Z. Metallkd, 1997, 88, 601.

13. XIAOMEI LI and M. J. STARINK, Mater. Sci. Forum, 2000, 313-317, 1071.

14. R.H. BROWN and L.A. WILLEY, 'Aluminium Vol. I: Properties, Physical Metallurgy and Phase Diagrams’, K. R. Van Horn, ed., 1967, ASM, Metals Park, Ohio, USA, p. 31.

15. M.J. STARINK and P.J. GREGSON, Scr. Metall. Mater., 1995, 33, 893.

16. M.J. STARINK and R.C. THOMSON, submitted to J. Mater. Sci. 


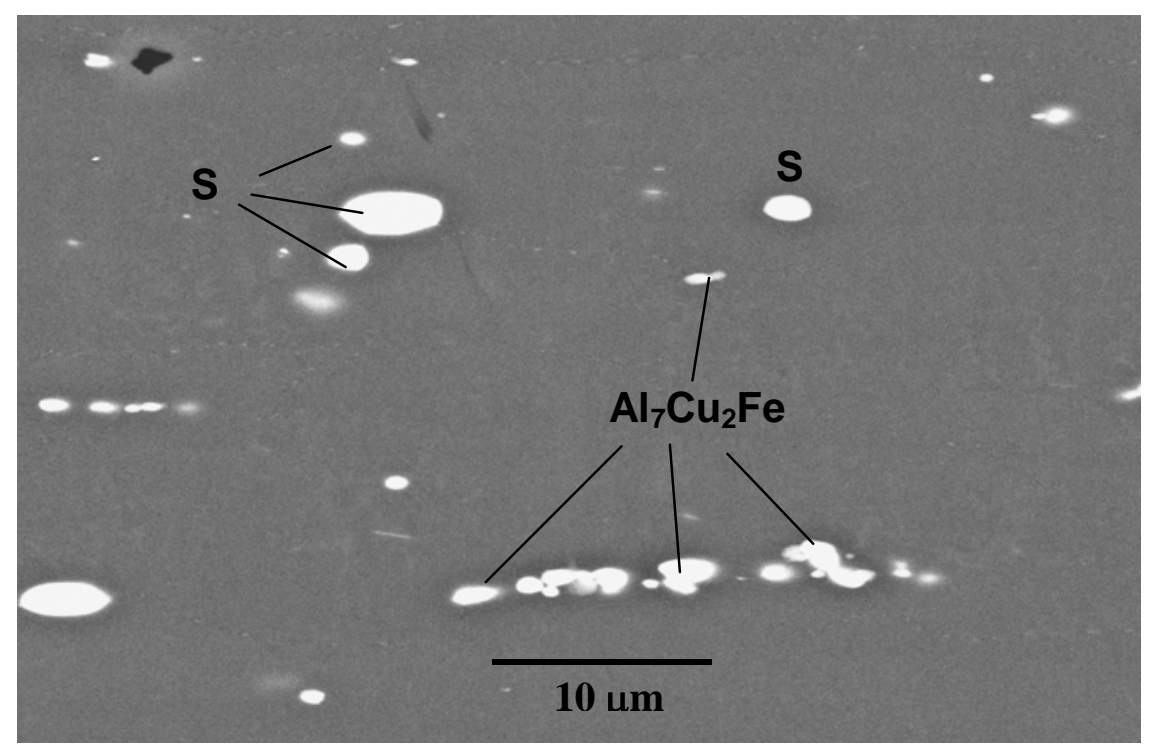

(a)

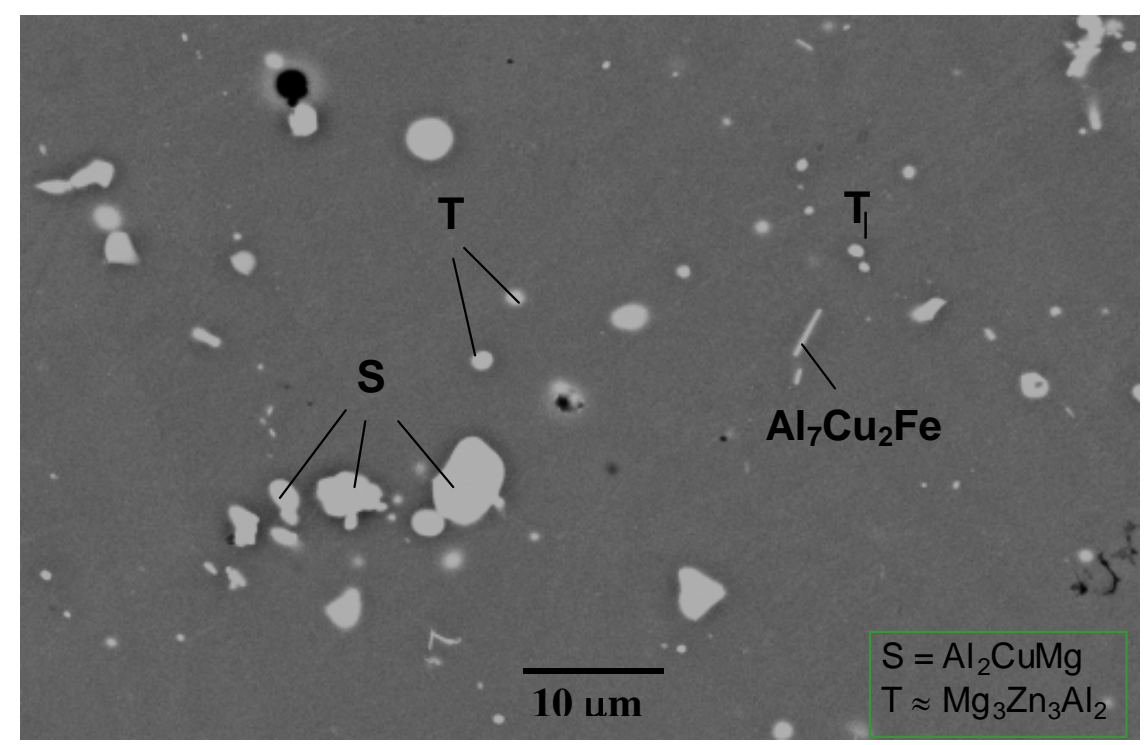

(b)

1 (a) SEM micrograph of alloy B (Al-6.1Zn-2.3Mg-2.6Cu), showing the main particles: $\mathrm{S}$ and $\mathrm{Al}_{7} \mathrm{Cu}_{2} \mathrm{Fe}$; (b) SEM micrograph of alloy $\mathrm{C}$ (Al-6.5Zn-3.0Mg-1.9Cu), showing the main particles: $\mathrm{S}$ and $\mathrm{T}$ phases. Both samples are T-S sections. 


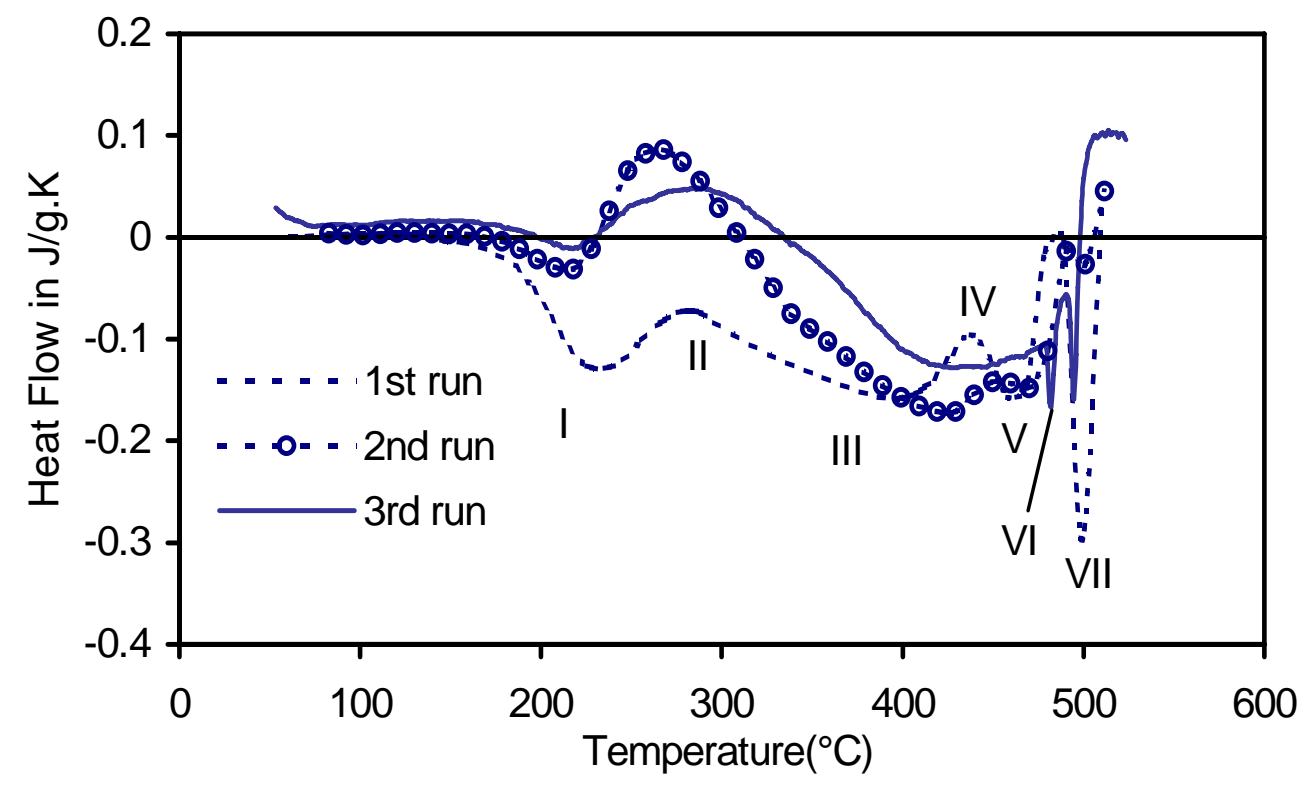

2 Three DSC runs of Alloy B (Al-6.1Zn-2.3Mg-2.6Cu) aged at $172^{\circ} \mathrm{C}$ for $16 \mathrm{~h}$, heating rate $10^{\circ} \mathrm{C} / \mathrm{min}$.

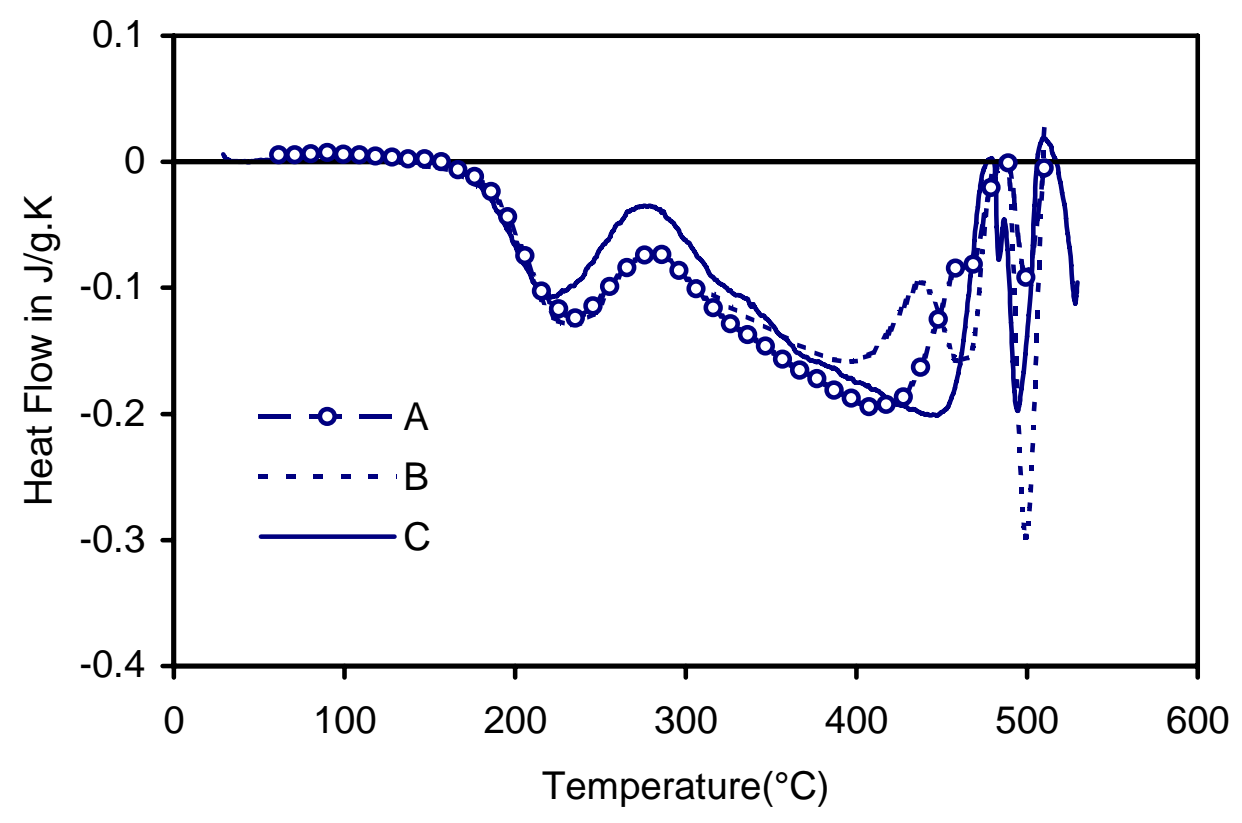

3 DSC curves of three alloys aged at $172^{\circ} \mathrm{C}$ for $16 \mathrm{~h}$, heating rate $10^{\circ} \mathrm{C} / \mathrm{min}$. A: medium $\mathrm{Cu}$ and medium Mg; B: high Cu; C: high Mg. 


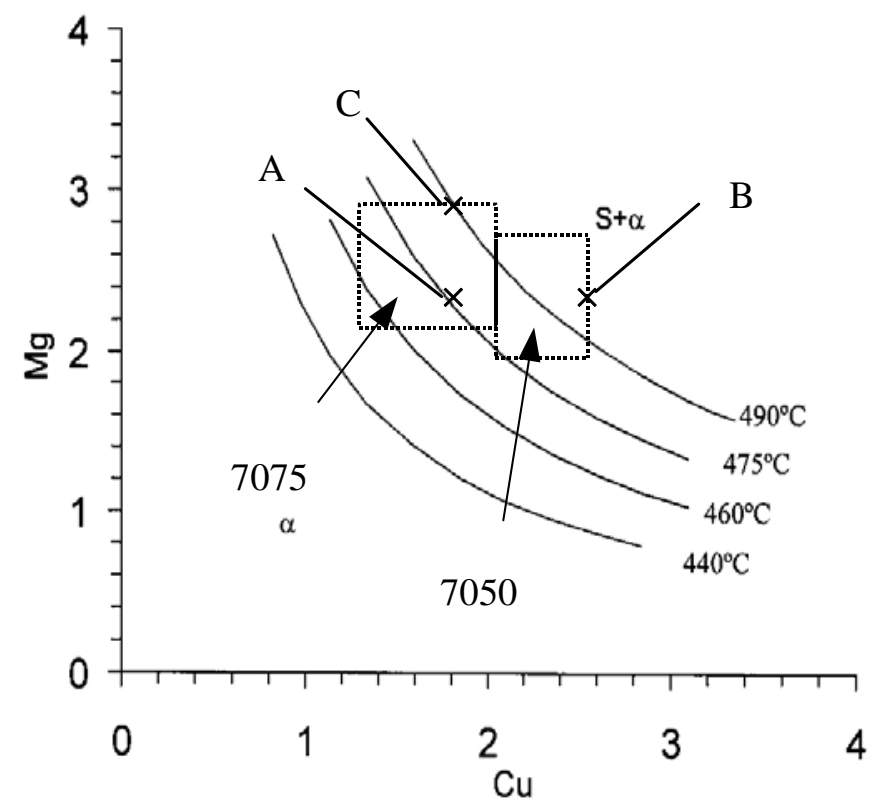

4 Solvi of S phase in Al-Zn-Mg-Cu with $\mathrm{Zn}=6 \mathrm{wt} \%$, temperature range $440-490^{\circ} \mathrm{C}$.

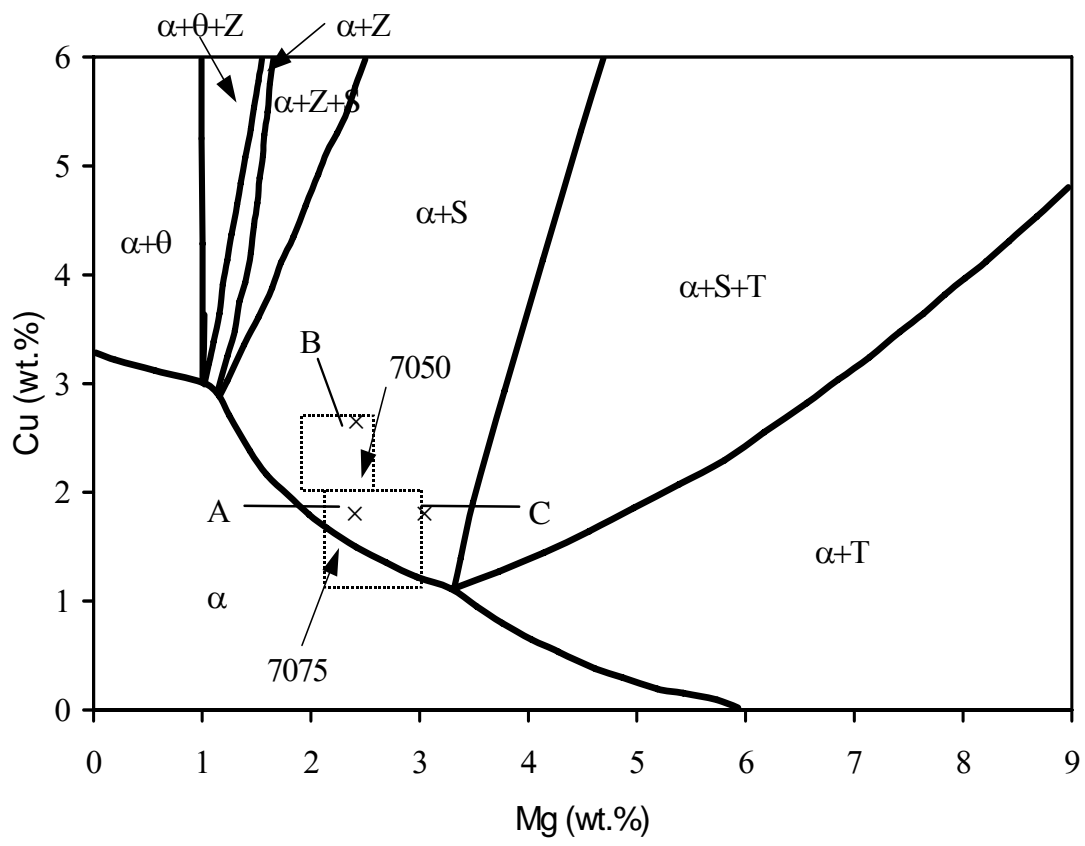

5 The quaternary system $\mathrm{Al}-\mathrm{Zn}-\mathrm{Mg}-\mathrm{Cu}$ at $460^{\circ} \mathrm{C}$ with $6 \% \mathrm{Zn}, \theta: \mathrm{CuAl}_{2}, \mathrm{Z}: \mathrm{Mg}_{2} \mathrm{Zn}_{11}$, data from Ref. [4]. 


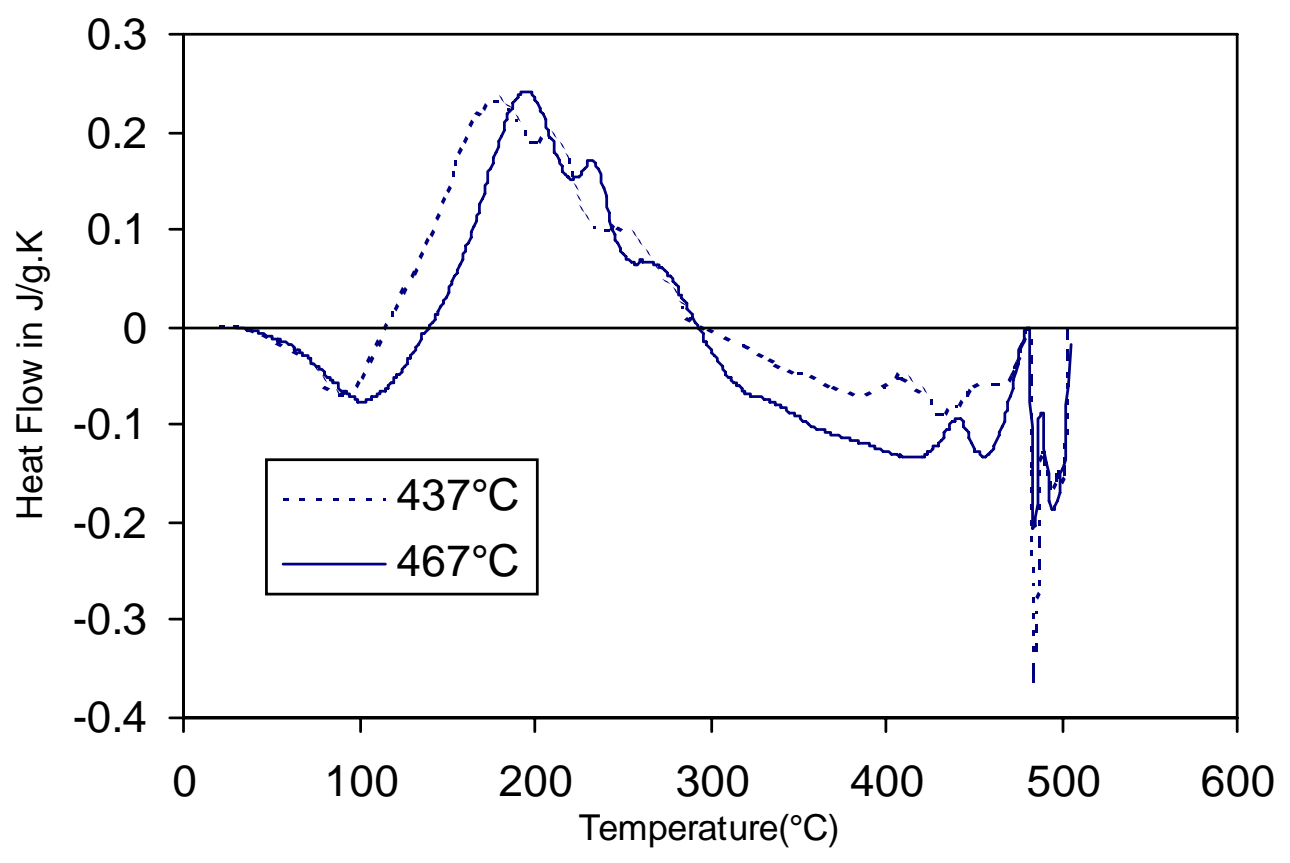

6 DSC curve of alloy C at different solution treatment temperatures: $437^{\circ} \mathrm{C}$ and $467^{\circ} \mathrm{C}$ for $1 \mathrm{~h}$. 